\title{
Sortilin Controls Intracellular Sorting of Brain-Derived Neurotrophic Factor to the Regulated Secretory Pathway
}

\author{
Zhe-Yu Chen, ${ }^{1,3}$ Alessandro Ieraci, ${ }^{1}$ Henry Teng, ${ }^{2}$ Henning Dall, ${ }^{5}$ Chui-Xiang Meng, ${ }^{4}$ Daniel G. Herrera, ${ }^{1}$ \\ Anders Nykjaer, ${ }^{5}$ Barbara L. Hempstead, ${ }^{2}$ and Francis S. Lee ${ }^{1}$ \\ ${ }^{1}$ Department of Psychiatry, and 2Division of Hematology, Department of Medicine, Weill Medical College of Cornell University, New York, New York 10021, \\ Departments of ${ }^{3}$ Neurobiology and ${ }^{4}$ Basic Medical Sciences, The Second Military Medical University, Shanghai 200433, People's Republic of China, and \\ ${ }^{5}$ Department of Medical Biochemistry, Aarhus University, DK-8000 Aarhus C, Denmark
}

Brain-derived neurotrophic factor (BDNF), after activity-dependent secretion from neurons, modulates critical nervous system functions. Recently, a variant in the human $b d n f$ gene, resulting in a valine to methionine substitution in the prodomain, has been shown to lead to defective regulated secretion from neurons and memory impairment. Here, we report a novel function for a Vps10p domain protein, sortilin, in controlling BDNF sorting to the regulated secretory pathway. Sortilin interacts specifically with BDNF in a region encompassing the methionine substitution and colocalizes with BDNF in secretory granules in neurons. A truncated form of sortilin causes BDNF missorting to the constitutive secretory pathway without affecting neurotrophin-4 (NT-4) secretion. In addition, sortilin small interfering RNA introduced into primary neurons also led to BDNF missorting from the regulated to the constitutive secretory pathway. Together, these data suggest a mechanism to understand the defect associated with variant BDNF and provide a framework, based on divergent presynaptic regulation of sorting to secretory pathways, to explain how two ligands for tropomyosin-related kinase $B$, BDNF and NT-4, can mediate diverse biological responses.

Key words: brain-derived neurotrophic factor; polymorphism; prodomain; sortilin; intracellular trafficking; regulated secretion

\section{Introduction}

Brain-derived neurotrophic factor (BDNF) plays key roles in vertebrate nervous system development and function (Tessarollo, 1998; Huang and Reichardt, 2001; Chao, 2003). A single nucleotide polymorphism in the $b d n f$ gene leading to a valine (Val) to methionine (Met) substitution at codon 66 in the prodomain $\left(\mathrm{BDNF}_{\mathrm{Met}}\right)$ was found to be associated with increased susceptibility in humans heterozygous for the polymorphism to neuropsychiatric disorders including Alzheimer's disease (Ventriglia et al., 2002), Parkinson's disease (Momose et al., 2002), depression (Sen et al., 2003), and bipolar disorder (Neves-Pereira et al., 2002; Sklar et al., 2002). In addition, humans heterozygous for BDN$\mathrm{F}_{\text {Met }}$ were shown to have memory impairments (Egan et al., 2003; Hariri et al., 2003; Rybakowski et al., 2003). Less is known about the molecular mechanisms underlying altered-variant BDNF functioning. When expressed by itself in hippocampal or cortical neurons, $\mathrm{BDNF}_{\mathrm{Met}}$ has reduced activity-dependent secretion

Received March 15, 2005; revised May 17, 2005; accepted May 18, 2005.

This work was supported by the DeWitt-Wallace Fund in the New York Community Trust (F.S.L., D.G.H., A.I.), National Alliance for Research on Schizophrenia and Depression (F.S.L., Z.-Y.C., D.G.H.), Nancy Pritzker Depression Network (F.S.L., D.G.H.), Foundation for the author of National Excellent Doctoral Dissertation of People's Republic of China (number 200229) (Z.-Y.C.), Shanghai Rising-Star Program (01QB14001) (Z.-Y.C.), National Natural Science Foundation of China (30000048) (Z.-Y.C.), and National Institutes of Health (NS052819 to F.S.L., NS30687 to B.L.H.). We thank Moses Chao, Frederick Maxfield, Pilar Perez, Claus Munck Petersen, and Kenneth Teng for helpful discussions.

Correspondence should be addressed to Francis S. Lee, Weill Medical College of Cornell University, 1300 York Avenue, Box 244, New York, NY 10021. E-mail: fslee@med.cornell.edu.

D0I:10.1523/JNEUROSCI.1017-05.2005

Copyright $\odot 2005$ Society for Neuroscience $\quad$ 0270-6474/05/256156-11\$15.00/0
(Egan et al., 2003; Chen et al., 2004). In addition, when expressed together in the same cell, $\mathrm{BDNF}_{\mathrm{Met}}$ alters the trafficking of wildtype BDNF $\left(\mathrm{BDNF}_{\mathrm{Val}}\right)$ through the formation of heterodimers that are less efficiently sorted into the regulated secretory pathway (Chen et al., 2004).

These initial findings are consistent with previous studies indicating that the prodomain of neurotrophins (NTs) plays important role in regulating their intracellular trafficking to secretory pathways (Suter et al., 1991). More specifically, in vitro secretion studies with $B D N F_{\text {Met }}$ point to the presence of a specific trafficking signal in the BDNF prodomain region encompassing the Met substitution that is required for efficient BDNF sorting to the regulated secretory pathway. The specific protein components of the regulated secretory machinery that interacts with a signal in the BDNF prodomain are not well established.

Recently, a Vps10p domain protein, sortilin (Sort), which is highly enriched in the vertebrate CNS (Sarret et al., 2003), was shown to bind to the prodomain of nerve growth factor (NGF) and to act as a cell-surface coreceptor with p75 to mediate proNGF-induced cell death (Nykjaer et al., 2004). However, the majority of sortilin ( $\sim 90 \%)$ resides in intracellular membranes, in particular, the Golgi apparatus (Petersen et al., 1997; Mazella, 2001; Nielsen et al., 2001). Sortilin also binds to other polypeptides such as neurotensin, sphingolipid activator protein (SAP), and lipoprotein lipase (LpL) and has been suggested to be involved in proper intracellular trafficking of these polypeptides to and from the Golgi apparatus (Petersen et al., 1997; Mazella et al., 1998; Munck Petersen et al., 1999; Nielsen et al., 1999; Lefrancois 
et al., 2003). Given its potential role in trafficking from the Golgi apparatus, as well as sequence homology of NGF and BDNF prodomains, we reasoned that sortilin might interact with the BDNF prodomain and mediate efficient intracellular targeting of proBDNF to secretory pathways. Here, we report that sortilin interacts specifically with the prodomain of BDNF in a discrete region containing the Met substitution. Our studies indicate that in neurosecretory and neuronal cells, sortilin is a key regulator of sorting of newly synthesized BDNF to appropriate secretory pathways.

\section{Materials and Methods}

Reagents and antibodies. Murine NGF was obtained from Harlan Bioproducts (Indianapolis, IN). Anti-FLAG antibodies were obtained from Sigma (St. Louis, MO) (monoclonal, M2, and polyclonal), and antihemagglutinin (anti-HA) antibodies were obtained from Covance (Denver, PA) (monoclonal, HA.11) and Sigma (polyclonal). Antisortilin antibodies were from BD Biosciences (Franklin Lakes, NJ), and anti-secretogranin II (SecII) antibodies were from Biodesign (Saco, ME). Anti-microtubule-associated protein 2 (anti-MAP2) and anti-tubulin antibodies were from Sigma. Fluorescent secondary antibodies were from Molecular Probes (Eugene, OR) and Jackson ImmunoResearch (West Grove, PA). The restriction enzymes were purchased from MBI Fermentas (Hanover, MD), and Pfu Turbo DNA was from Stratagene (La Jolla, CA). All other compounds were from Sigma.

DNA constructs. The human BDNF and NT-4 cDNA were subcloned into pCDNA3.1hygro expression vector (Invitrogen, San Diego, CA) using HindIII and XhoI sites. The HA epitope tag was added to either the $5^{\prime}$ or $3^{\prime}$ end of the BDNF or NT-4 cDNA by PCR method. The BDNF Val-to-Met mutation at position 66 was generated by means of two-step PCR. All the BDNF mutant constructs have a HA tag at the $3^{\prime}$ end and were generated by means of two-step PCR method. Human sortilin cDNA was subcloned into pCDNA3.1hygro expression vector (Invitrogen) using NheI and XhoI sites. A Myc tag was inserted three residues after the furin site by PCR method. Myc-tagged truncated sortilin was generated by PCR to amplify the luminal domain of sortilin and cloned into pCDNA3.1hygro vector using NheI and XhoI sites.

A recombinant adenovirus encoding BDNF was prepared as described previously (Lee et al., 2001). A recombinant adenovirus for expression of truncated human sortilin (amino acids 1-725) was generated as follows: pCDNA3.1/Zeo $(-)$ encoding the luminal domain of sortilin (Munck Petersen et al., 1999) was digested with XbaI and PmeI, and the resultant fragment was inserted into PAC-CMVpLqA (Gomez-Foix et al., 1992) cut with HindIII, blunted, and further digested with $\mathrm{XbaI}$. Twenty micrograms of the soluble sortilin/PAC-CMVpLqA shuttle plasmid and 25 $\mu \mathrm{g}$ of pJM17 (McGrory et al., 1988) encoding part of the Ad5 genome were subsequently cotransfected into human embryonic kidney 293 (HEK 293) cells. Plaques detected $10 \mathrm{~d}$ after transfection were picked and tested for the ability to induce expression of truncated sortilin by Western blotting. Positive colonies were propagated and adenovirus purified by $\mathrm{CsCl}$ centrifugation according to standard procedures. The number of pfus was $\sim 10^{10}$ per milliliter.

Viral vectors are derived from the human immunodeficiency virusbased lentiviral backbones provided by Dr. Kerry Ressler (Emory University, Atlanta, GA). The lentivirus plasmid containing green fluorescent protein (GFP) is the pWPT-GFP. The BDNF1GFP and BDNF23GFP fragments are generated by PCR to fuse BDNF encoding amino acids $19-43$ and $44-102$, respectively, to GFP. The BDNF1GFP and BDNF23GFP fragments were subcloned into the pWPT-GFP plasmid to replace the GFP fragment using BamHI and SalI sites.

Preparation of viral stocks. Virus was generated by transient cotransfection of the expression plasmid $(20 \mu \mathrm{g})$, vesicular stomatitis virus $\mathrm{G}$ pseudotyping construct $(10 \mu \mathrm{g})$, and the packaging construct pCMVR8.91 $(20 \mu \mathrm{g})$ into a $150 \mathrm{~mm}$ plate of $90 \%$ confluent HEK $293 \mathrm{~T}$ cells. Medium was collected 48 and $72 \mathrm{~h}$ after transfection, cleared of debris by low-speed centrifugation, and filtered through $0.45 \mu \mathrm{m}$ filters. High-titer stocks were prepared by an initial ultracentrifugation for $1 \mathrm{~h}$ at $23,000 \mathrm{rpm}(\mathrm{SW}-28$ rotor) and a secondary centrifugation at $13,000 \times g$ for $30 \mathrm{~min}$. Viral titers were determined by infection of HEK 293T cells. GFP-positive cells were visualized by fluorescent microscopy. Viral pellet was resuspended in $1 \% \mathrm{BSA} / \mathrm{PBS}$ and stored at $80^{\circ} \mathrm{C}$. After concentration, viral titers will be $\sim 3 \times 10^{7}-7 \times 10^{7}$ transducing units $/ \mathrm{ml}$. Pheochromocytoma PC12 cells were infected with the lentivirus containing GFP, Box1-GFP, or Box2+3-GFP gene for $24 \mathrm{~h}$ at a titer of $100 \%$, followed by a $24 \mathrm{~h}$ incubation in DMEM containing L-glutamine ( $1 \mathrm{mM})$.

Sortilin small interfering RNA. Knock-down of sortilin using RNA oligonucleotides was achieved by transfection of duplex RNA oligonucleotides (Dharmacon, Lafayette, $\mathrm{CO}$ ) corresponding to part of the coding region of sortilin (aatgttccaatggccccactc), as described previously (Lefrancois et al., 2003, 2005). Primary hippocampal-cortical neurons were transfected with duplex RNA oligonucleotides by electroporation (Amaxa, Cologne, Germany), as described previously (Gresch et al., 2004) and experiments performed $3 \mathrm{~d}$ after transfection.

PC12 and HEK 293 cell culture and immunoprecipitation and immunoblotting. PC12 (615) cells stably overexpressing tropomyosin-related kinase A (TrkA) receptors (Hempstead et al., 1992) were maintained in DMEM (Invitrogen) containing 10\% fetal bovine serum (Invitrogen), $5 \%$ horse serum (Invitrogen), supplemented with $100 \mathrm{U} / \mathrm{ml}$ penicillin/ streptomycin (Invitrogen), and $2 \mathrm{~mm}$ glutamine plus $200 \mu \mathrm{g} / \mathrm{ml} \mathrm{G} 418$ (Invitrogen). HEK 293 cells were maintained in DMEM containing 10\% fetal bovine serum, supplemented with $100 \mathrm{U} / \mathrm{ml}$ penicillin, $100 \mathrm{U} / \mathrm{ml}$ streptomycin, and $2 \mathrm{~mm}$ glutamine. Lipofectamine 2000 (Invitrogen) was used to transfect DNA in cells. Forty-eight hours after transfection, lysates were collected and analyzed by Western blot as described previously (Lee and Chao, 2001). Briefly, for immunoprecipitation experiments, lysates were collected and incubated with polyclonal HA antibody (Sigma) followed by incubation with protein A-Sepharose beads (Sigma). Western blots were performed by separating proteins via SDSPAGE, transferring to a polyvinylidene difluoride membrane (Bio-Rad, Hercules, CA) and immunoblotting with HA.11 (Covance). The immunoreactive protein bands were detected by enhanced chemiluminescence (Pierce, Rockford, IL). For densitometric analysis, immunoreactive bands were scanned and intensity quantitated using NIH Image (Scion, Frederick, MD).

To construct HEK 293 cells stably expressing mouse proBDNF, fulllength BDNF cDNA (kindly received as a gift from Dr. Lino Tessarollo, National Cancer Institute, Frederick, MD) was mutagenized at the furin site (Arg129Ala/Arg130Ala) to generate furin-resistant proBDNF. In addition, the termination codon was replaced with a hexahistidine tag at the C terminus, followed by the termination codon. A $5^{\prime}$ BglII and $3^{\prime}$ XhoI sites were added to the cDNA. DNA fragment containing the proBDNF was subcloned into pcDNA3.1 $(+)$ (Invitrogen) digested previously with the same two enzymes. HEK 293 cells were transfected with the plasmid construct using Lipofectamine, and stable clones overexpressing furinresistant proBDNF-His were selected with HEK 293 media (described above) supplemented with $500 \mu \mathrm{g} / \mathrm{ml} \mathrm{G418}$. To investigate the effects of overexpressing truncated sortilin on proBDNF secretion, the stable cells were infected with adenovirus overexpressing either GFP or truncated sortilin (described above) at multiplicity of infection of 1 . Conditioned media were harvested after $48 \mathrm{~h}$ after infection and analyzed on Western blot using anti-BDNF and anti-sortilin antibodies.

Preparation of glutathione S-transferase fusion proteins and in vitro binding assays. The glutathione $S$-transferase (GST)-proneurotrophin constructs are pGEX-Val containing wild-type BDNF encoding amino acids 44-102, pGEX-Met containing variant BDNF encoding amino acids 44-102, with Met at position 66, pGEX-NT4 (provided by Claus Munck Petersen, Aarhus University) containing NT-4 encoding amino acids 25-76. These cDNA fragments were generated by PCR and subcloned into the pGEX-6P1 vector (Amersham Biosciences, Arlington Heights, IL), respectively using BamHI and XhoI sites. GSTproBDNF(Val), GST-proBDNF(Met), and GST-proNT-4 proteins were expressed in Escherichia coli and immobilized on glutathione-Sepharose 4B beads (Amersham Biosciences). HEK 293 cell lysates overexpressing sortilin were prepared as described above and incubated with immobilized GST fusion proteins at $4^{\circ} \mathrm{C}$. The beads were then washed, and the bound proteins were analyzed by SDS-PAGE followed by staining with Coomassie blue (Sigma) or immunoblotting with anti-sortilin antibod- 
ies. For endogenous interaction, hippocampi or cortices were dissected from postnatal day $10(\mathrm{P} 10)$ rat brains and homogenized and lysed in 10 mm Tris, $\mathrm{pH} 7.5,150 \mathrm{~mm} \mathrm{NaCl}, 1 \mathrm{~mm}$ EDTA, and 0.5\% NP-40 with protease and phosphatase inhibitors. After centrifugation and preclearing with protein A-Sepharose beads, lysates were incubated with antiBDNF antibody (Santa Cruz Biotechnology, Santa Cruz, CA) or normal rabbit IgG (Santa Cruz Biotechnology). The immunocomplex was precipitated using protein A-Sepharose beads and analyzed by immunoblotting with anti-sortilin antibodies (BD Biosciences).

Neuronal cell cultures. Dissociated primary cultures of hippocampal and hippocampo-cortical neurons from embryonic day 18 (E18) rats were prepared from timed-pregnant Sprague Dawley rats. Fetuses were removed under sterile conditions and kept in PBS on ice for microscopic dissection of the hippocampi. The meninges were removed and the tissue was placed in Neurobasal media (Invitrogen). The tissue was briefly minced with fine forceps and then triturated with a fire-polished Pasteur pipette. Cells were counted and plated on culture wells coated with 0.01 $\mathrm{mg} / \mathrm{ml}$ poly-D-lysine overnight in a Neurobasal medium containing B27 supplement (Invitrogen) and L-glutamine (0.5 mM) (Invitrogen). Experiments were conducted 3-4 d after plating.

Immunocytochemical staining and fluorescence microscopy. PC12 (615) cells or hippocampal neurons were grown on glass coverslips (Corning, Corning, NY) coated with poly-L-lysine (Sigma) and transfected with epitope-tagged neurotrophin constructs. Forty-eight hours after transfection, cells were fixed with a $4 \%$ paraformaldehyde solution in PBS and permeabilized with brief treatment with cold methanol ( $5 \mathrm{~min}$ ), followed by washing with PBS three times. Cells were blocked with 5\% milk in PBS for $30 \mathrm{~min}$. Specimens were incubated with primary antibodies and then incubated with subtype-specific fluorescenated secondary antibodies. Stained PC12 specimens were examined by epifluorescence microscopy using a CoolSNAP CCD camera (PhotoMetrics, Huntington Beach, CA) mounted on a Nikon (Tokyo, Japan) TE2000 microscope equipped with a motorized $\mathrm{Z}$ drive and either a $100 \times$ numerical aperture 1.4 (NA1.4) objective or $60 \times$ NA1.4 objective and standard FITC/Texas Red dichroic filter sets. Confocal fluorescence microscopy was performed on hippocampal neuron specimens using a Zeiss (Oberkochen, Germany) LSM510 microscope fitted with a Zeiss $63 \times$ NA1.4 objective with standard filter sets and standard (1 Airy disk) pinhole.

Quantitative analysis of fluorescent images. To quantitate the proportion of colocalization between BDNF or NT-4 and the secretory granule marker, SecII or sortilin, PC12 cells were examined by epifluorescence microscopy using appropriate filter sets to selectively detect Alexa488 (FLAG) and cyanine 3 (SecII). Optical slices were obtained by the use of the $\mathrm{Z}$ drive mounted on a Nikon TE2000 microscope, and the slice containing the maximal fluorescent intensity was chosen. For hippocampal neurons, multiple optical confocal images $(0.8 \mu \mathrm{m})$ were obtained across the $z$-axis, and the slice containing the maximal fluorescent intensity was chosen. Staining intensity for each fluor and the proportion of colocalization was quantitated using the colocalization module in the MetaMorph software (Universal Imaging Corporation, West Chester, PA). Approximately 30 cells were examined at random, and colocalization was calculated for the entire cell. The results of three independent experiments were compiled and SEM between these experiments indicated in the error bars.

ELISA. PC12 (615) cells $\left(4.5 \times 10^{5}\right)$ were seeded to six-well plates. One day before transfection, cells were placed in differentiation media $(1.5 \%$ horse serum, $1 \%$ fetal bovine serum, and $50 \mathrm{ng} / \mathrm{ml} \mathrm{NGF}$ ). Then, $4 \mu \mathrm{g}$ of $\mathrm{BDNF}_{\mathrm{Val}}$ or $4 \mu \mathrm{g}$ of NT- 4 construct in the presence or absence of $4 \mu \mathrm{g}$ of truncated sortilin was added per well. Forty-eight hours after transfection, cells were washed three time with Krebs'-Ringer's-Henseleit (KRH) buffer with the following composition (in $\mathrm{mM}$ ): $125 \mathrm{NaCl}, 4.8$ $\mathrm{KCl}, 2.6 \mathrm{CaCl}_{2}, 25 \mathrm{HEPES}, 1.2 \mathrm{MgSO}_{4}, 5.6$ glucose, 1 sodium ascorbate, and $1.2 \mathrm{KH}_{2} \mathrm{PO}_{4}$, adjusted to $\mathrm{pH} 7.4$ with $\mathrm{NaOH}$. The conditioned media were collected after a $16 \mathrm{~h}$ incubation at $37^{\circ} \mathrm{C}$ and used as a measure of constitutive secretion. To determine regulated secretion, cells were washed three times with KRH buffer, followed by a 10 min incubation at $37^{\circ} \mathrm{C}$ in stimulated media [ $\mathrm{KRH}$ buffer with an increased $\mathrm{KCl}$ concentration (56 mM) and decreased $\mathrm{NaCl}$ concentration $(75 \mathrm{~mm})$ ]. Secretions results from the constitutive secretion condition was normalized to 10
A

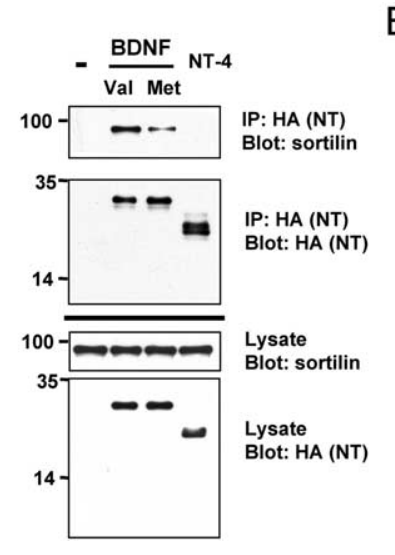

B

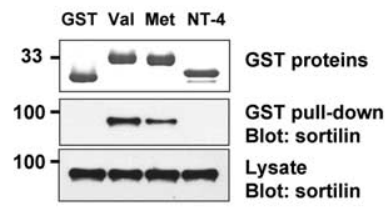

Figure 1. Coimmunoprecipitation of sortilin with wild-type and variant BDNF. A, HEK 293 cells were cotransfected with $\mathrm{CDNAs}$ encoding sortilin and $C$-terminal $B \mathrm{BNF}_{\mathrm{Val}}-\mathrm{HA}$ or $\mathrm{BDNF}_{\text {Met }}-\mathrm{HA}$ or empty vector $(-)$. Cell lysates were immunoprecipitated with $\mathrm{HA}$ antibodies and immunoblotted with sortilin antibodies (top). Immunoprecipitation (IP) of BDNF-HA was confirmed by immunoblotting with $\mathrm{HA}$ antibodies (middle). Crude lysates were immunoblotted with sortilin antibodies and $\mathrm{HA}$ antibodies to confirm equivalent expression level (bottom). $\boldsymbol{B}, \mathrm{In}$ vitro binding assay. GST-BDNF ${ }_{\mathrm{Val}^{\prime}}, \mathrm{GST}-\mathrm{BDNF}_{\mathrm{Met}^{\prime}}$ or GST-NT-4 prodomain fusion proteins were incubated with lysates from HEK 293 cells overexpressing full-length sortilin. Bound sortilin was detected by immunoblotting with anti-sortilin antibody.

min. The BDNF protein concentrations in the respective media samples were determined using the BDNF Emax ImmunoAssay system (Promega, Madison, WI) with recombinant BDNF as a standard. Standards and samples were performed in duplicates, and each group contains six independent samples. After collecting condition media, cells were fixed and immunostained to determine the transfection efficiency. Each sample has a consistent transfection efficiency of $\sim 30 \%$.

\section{Results}

\section{Mapping the BDNF-sortilin interaction}

In light of the Met substitution leading to altered BDNF activitydependent secretion, we sought to identify potential trafficking proteins that interact with the BDNF prodomain region encompassing the Met substitution. We focused on sortilin, a Vps10p domain protein, because it has been established to control the intracellular trafficking from the Golgi for a variety of polypeptides, including neurotensin, SAP, and LpL (Petersen et al., 1997; Mazella et al., 1998; Munck Petersen et al., 1999; Nielsen et al., 1999; Lefrancois et al., 2003). First, we investigated whether sortilin interacted with BDNF. We expressed both full-length versions of sortilin and C-terminal HA epitope-tagged BDNF (BDNF-HA) in HEK 293 cells. After immunoprecipitation of BDNF with HA antibodies, an association was observed with sortilin, as assessed by Western blot analysis using sortilin antibodies (Fig. 1A). As a control, we assessed whether a C-terminal HA epitop-tagged NT-4 (NT-4-HA), a neurotrophin family member that has little sequence homology with BDNF in the prodomain region (Berkemeier et al., 1991; Hallbook et al., 1991; Ip et al., 1992), associated with sortilin. Unlike BDNF, when coexpressed with sortilin and immunoprecipitated from HEK 293 cells with HA antibodies, NT-4 did not coimmunoprecipitate with sortilin (Fig. 1A). Furthermore, when a C-terminal epitopetagged (HA) version of the variant BDNF (Val66Met) was cotransfected with sortilin and immunoprecipitated with HA antibodies, a significantly reduced association with sortilin was observed (Fig. 1A). Quantitation of the Western blots as a percentage of sortilin coimmunoprecipitation by wild-type BDNF indicated a significant decrease in interaction of $\mathrm{BDNF}_{\mathrm{Met}}$ with sortilin ( $51 \pm 6 \%$ of wild-type BDNF control; $p<0.01$; Student's $t$ test). 


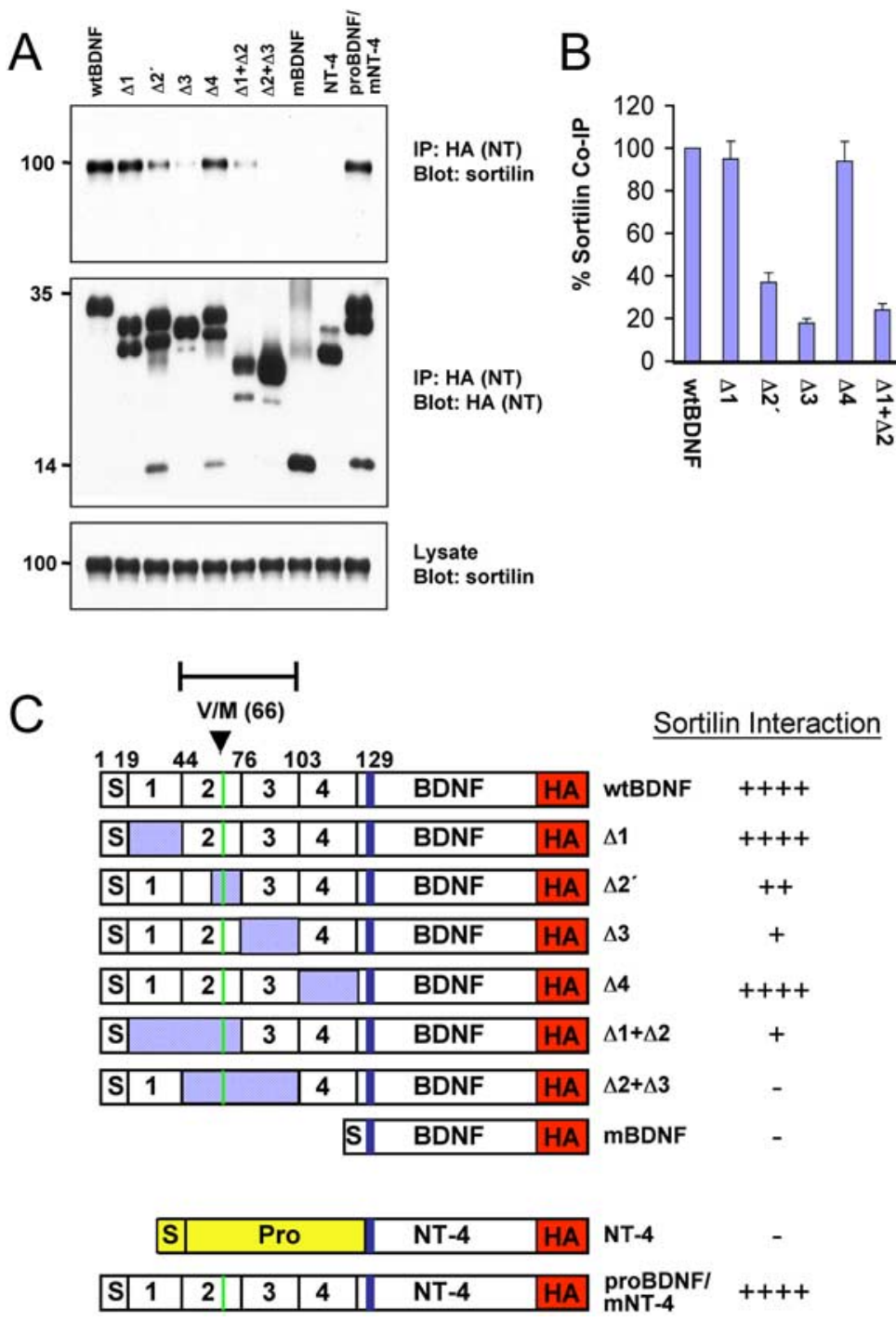

Figure 2. Mapping the interaction of sortilin with BDNF mutants. A, HEK 293 cells were cotransfected with sortilin and either full-length BDNF or NT-4 or truncation mutants. Lysates were immunoprecipitated with HA antibodies and immunoblotted with sortilin antibodies (top). Immunoprecipitation of BDNF-HA was confirmed by immunoblotting with HA antibodies (middle). Sortilin expression was verified with sortilin antibodies (bottom). $\boldsymbol{B}$, Quantitation of Western blots in the top panel of $\boldsymbol{A}$ as a percentage of sortilin coimmunoprecipitation (Co-IP) by mutant neurotrophins compared with wild-type BDNF. Mean proportions \pm SEM were determined from analysis of three independent experiments. C, Summary of BDNF and NT-4 mutants used in $A$ and a summary of the sortilin interactions with the mutant BDNF and NT-4. IP, Immunoprecipitation; wt, wild type; $m$, mature.

To confirm that this altered interaction was specific to the prodomain region, in vitro binding studies were performed. GST fusion proteins containing a portion of the BDNF prodomain encompassing the Val/Met substitution (amino acids 44-102) or the NT-4 prodomain (amino acids 25-76) were immobilized on glutathione beads and incubated with HEK 293 cell lysates overexpressing sortilin (Fig. $1 \mathrm{~B}$ ). Strong binding of sortilin was observed with the GST-prodomain fusion protein containing the wild-type BDNF prodomain (Val). Weaker binding was observed with the GST-prodomain fusion protein containing the variant BDNF prodomain (Met). No binding of sortilin was observed with the GST-NT-4 prodomain fusion protein. Together, these results are consistent with the coimmunoprecipitation studies (Fig. $1 A$ ) and point to a specific region in BDNF encompassing the Met substitution as critical for binding to sortilin.

Additional coimmunoprecipitation experiments were per- formed with a series of deletions of BDNF that eliminated regions of the prodomain (Fig. $2 \mathrm{~A}$ ). The BDNF prodomain were divided into four "boxes" (Fig. 2C) based on amino acid conservations between BDNF, NGF, and NT-3, as was designated previously in a mutagenesis study of the NGF prodomain (Suter et al., 1991). The entire BDNF prodomain was capable of binding to sortilin, and removal of Box 1 (amino acids 19-43) or Box 4 (amino acids 103-120) had no effect on the baseline level of interaction with sortilin (Fig. $2 A, B$ ). However, removal of a portion of Box $2\left(\Delta 2^{\prime}\right.$; amino acids 62 79) that contains the $\mathrm{Val} / \mathrm{Met}$ substitution site, Box 1, and Box 2 or the entire Box 3 (amino acids 76-102) significantly disrupted BDNF interaction with sortilin (Fig. $2 A, B)$. Removal of both Box 2 and Box 3 (amino acids 44-102) abolished the interaction. Together, these results indicate that Box 2 and Box 3 mediate the interaction with sortilin, which is consistent with the GST pull-down experiments in which this same region (amino acids 44-103) was capable of precipitating sortilin (Fig. $1 \mathrm{~B}$ ). Conversely, swapping the BDNF prodomain into NT-4 led to significant association of the BDNF/ NT-4 chimera with sortilin, confirming that the BDNF prodomain alone is sufficient to mediate interaction with sortilin.

In addition, a truncated form of sortilin containing only the luminal domain (amino acids 1-755) was able to associate with BDNF at the same level as full-length sortilin (Fig. 3A). On other hand, a GFP fusion protein containing only the sortilin transmembrane and cytoplasmic domain did not interact with BDNF (supplemental Fig. 1, available at www.jneurosci.org as supplemental material). These coprecipitation studies suggested that the BDNF association with sortilin specifically involves the luminal domain of sortilin and a discrete region of the BDNF prodomain (amino acids 44102) that includes the site of Met substitution.

The association of BDNF and sortilin was based on cotransfection experiments in HEK 293 cells. To examine whether this interaction occurs under physiological conditions, we performed additional coimmunoprecipitation experiments of endogenous proBDNF and sortilin proteins from brain lysates from two regions, hippocampus and cortex. Lysates from P10 rat hippocampus or cortex were immunoprecipitated with anti-BDNF antibody and the immunocomplex analyzed by immunoblotting with anti-sortilin antibody. As shown in Figure $3 B$, the $95 \mathrm{kDa}$ sortilin protein coimmunoprecipitated with proBDNF similarly from both brain regions. This result indicates that an endogenous association of proBDNF could be detected with sortilin in brain tissues.

\section{Effect of sortilin on constitutive BDNF secretion}

Because sortilin appeared to interact specifically with BDNF, we then hypothesized that sortilin may regulate intracellular BDNF 
trafficking and release. We first assessed the effects of sortilin on BDNF secretion in the same heterologous cell line, HEK 293 cells, which endogenously express low levels of sortilin (Nykjaer et al., 2004) and only has a constitutive secretory pathway. We postulated that the luminal portion of sortilin, which interacts with BDNF (Fig. $1 E)$, may alter BDNF trafficking, because it lacks the appropriate post-Golgi trafficking signals located in the cytoplasmic domain (Nielsen et al., 2001). HEK 293 cells, stably expressing proBDNF, were infected with recombinant adenovirus expressing GFP or the truncated form of sortilin (tSort). Constitutive BDNF secretion was assessed $48 \mathrm{~h}$ later by Western blot analysis of media collected from infected cells. There was a significant increase in the amount of BDNF detected in the media from cells expressing the tSort when compared with cells expressing GFP (Fig. 3C). This result suggests that sortilin is involved in mediating BDNF secretion from this heterologous cell line, in that a truncated form of sortilin altered the amount of BDNF secreted.

\section{Intracellular localization of BDNF and sortilin in neurosecretory and neuronal cells}

Because HEK 293 cells have only a constitutive secretory pathway, we then investigated the effect of the sortilin-BDNF interaction in regulating BDNF trafficking in neurosecretory cells and neurons. In these cells, there are both constitutive and the regulated secretory pathways, and BDNF is primarily secreted via the regulated secretory pathway $(\mathrm{Lu}, 2003)$. First, we wanted to assess whether sortilin and BDNF were expressed in the same intracellular compartment in neurosecretory cells as well as neurons. By immunofluorescent microscopy, we determined the intracellular distribution of sortilin and $\mathrm{BDNF}_{\mathrm{Val}}$. In differentiated PC12 cells, we transfected an $\mathrm{N}$-terminal epitope-tagged $\mathrm{BDNF}_{\mathrm{Val}}$ $\left(\mathrm{HA}-\mathrm{BDNF}_{\mathrm{Val}}\right)$, which allowed us to visualize the pool of intracellular proBDNF, and costained for both the HA tag and endogenous sortilin (Fig. $4 A$ ). There was significant $(\sim 80 \%)$ colocalization of sortilin and $\mathrm{BDNF}_{\mathrm{Val}}$ in the entire cell including both perinuclear and distal neurite regions. In particular, in the distal neurites, sortilin and BDNF colocalized in punctate structures. Furthermore, a similar pattern of colocalization of Myc-sortilin and $\mathrm{HA}-\mathrm{BDNF}_{\mathrm{Val}}$ in punctate structures was also observed in primary hippocampal neurons (Fig. $4 B$ ). To determine whether the variant $\mathrm{BDNF}_{\mathrm{Met}}$ had an altered colocalization with sortilin, compared with wild-type $\mathrm{BDNF}_{\mathrm{Val}}, \mathrm{HA}-\mathrm{BDNF}_{\mathrm{Met}}$ was transfected into differentiated PC12 cells and costained with HA and sortilin antibodies. There was decreased colocalization of HA$\mathrm{BDNF}_{\mathrm{Met}}$ with endogenous sortilin compared with $\mathrm{BDNF}_{\mathrm{Val}}$ as determined by quantitative analysis of the proportion of colocalization between BDNF and sortilin in the entire cell determined from analyses of three independent experiments (Val, $78 \pm 7 \%$; Met, $47 \pm 5 \%$; $p<0.01$; Student's $t$ test).

In particular, because there was decreased distribution of BDNF $_{\text {Met }}$ in the distal neurites, there was less colocalized in that region of the cell. In addition, in hippocampal neurons, $\mathrm{BDNF}_{\mathrm{Met}}$
B C
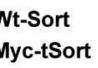

BDNF-HA

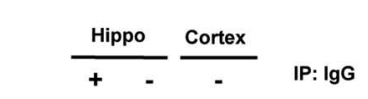

Blot: sortilin
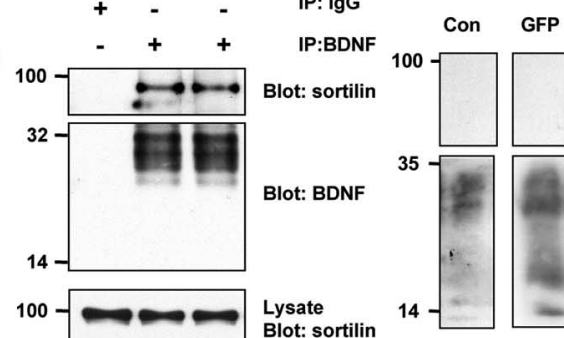

tSort

Media

Blot: sortilin

Media

Blot: BDNF

\section{Lysate}

Blot: sortilin

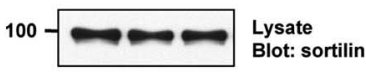

Lysate
Blot: sortili

14

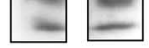

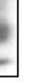

Figure 3. Mapping the interaction of BDNF with sortilin mutants. A, Coimmunoprecipitation of tSort with BDNF. HEK 293 cells

also had reduced colocalization with sortilin, compared with $\mathrm{BDNF}_{\mathrm{Val}}(\mathrm{Val}, 66 \pm 4 \%$; Met, $38 \pm 3 \%$; $p<0.01$; Student's $t$ test).

Because BDNF has been shown to be targeted to secretory granules in neurons and PC12 cells (Moller et al., 1998; Mowla et al., 1999; Wang et al., 2004), we assessed whether sortilin colocalized in the same compartment in differentiated PC12 cells (Fig. $4 A$ ). We assessed sortilin colocalization with SecII, an established marker of secretory granules in the regulated secretory pathway (Huttner et al., 1991; Halban and Irminger, 1994; Ozawa and Takata, 1995). There was significant colocalization of endogenous sortilin and SecII, especially in punctate structures in the distal neurites (Fig. 4A). In hippocampal neurons, endogenous sortilin also had significant colocalization with SecII (Fig. 4B), confirming that sortilin is properly localized in the secretory granule compartment as BDNF destined for secretion. Quantitating colocalization of endogenous sortilin with SecII in hippocampal neurons revealed that there was significant localization $(80 \pm 5 \%)$ of sortilin to SecII-positive compartments. Because BDNF has been established to reside in neurons in SecII-positive secretory granules (Berg et al., 2000), sortilin is properly localized in neurons to interact with and regulate BDNF trafficking. Furthermore, these results are consistent with previous studies demonstrating that less $\mathrm{BDNF}_{\mathrm{Met}}$ compared with $\mathrm{BDNF}_{\mathrm{Val}}$ was targeted to SecII-positive secretory granules in neurosecretory cells as well as neurons (Egan et al., 2003; Chen et al., 2004).

In the context of sortilin colocalizing with BDNF in the secretory granule compartment, we performed experiments to determine whether it was feasible for such an interaction to occur under the acidic conditions in the lumen of secretory granules. The $\mathrm{pH}$ dependence of the sortilin-BDNF interaction was assessed by coimmunoprecipitation studies from HEK 293 cells lysates, based on the assumption that the intraluminal $\mathrm{pH}$ in mature secretory granules is pH 5.5 (Johnson and Scarpa, 1976; Hutton, 1982). In these coimmunoprecipitation studies, sortilin binds to the same level at $\mathrm{pH} 7.4$ compared with $\mathrm{pH} 5.5$ but is shown not to bind at $\mathrm{pH} 3.5$ (supplemental Fig. 2, available at 
A
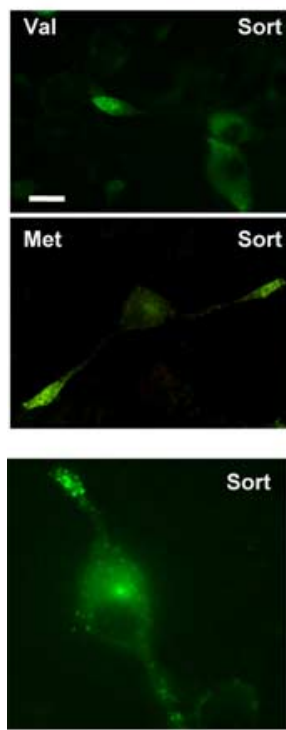
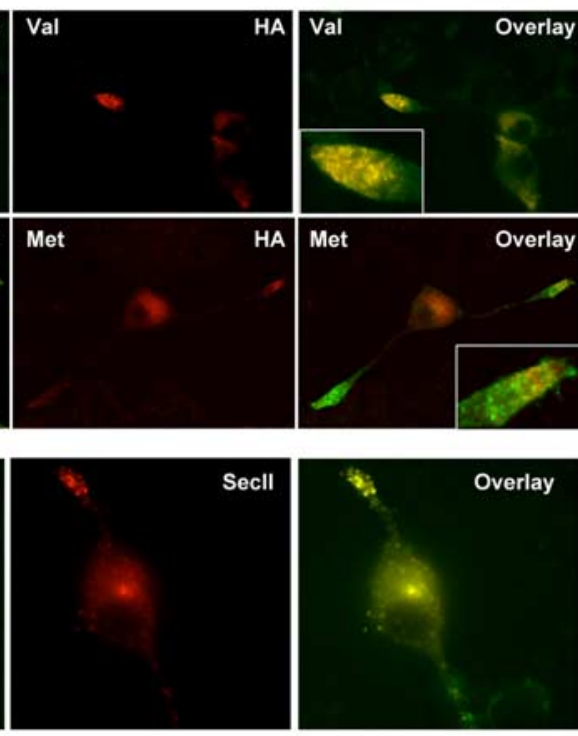

B
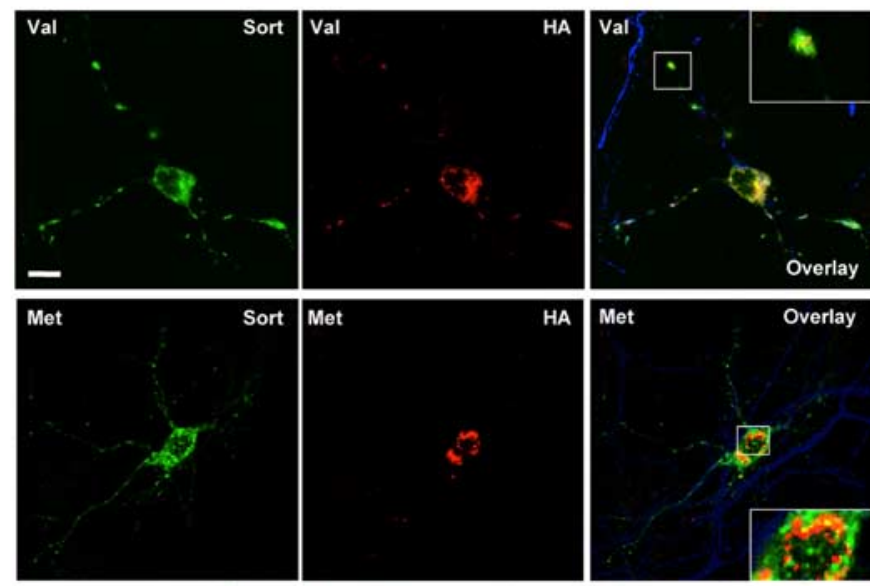

Overlay
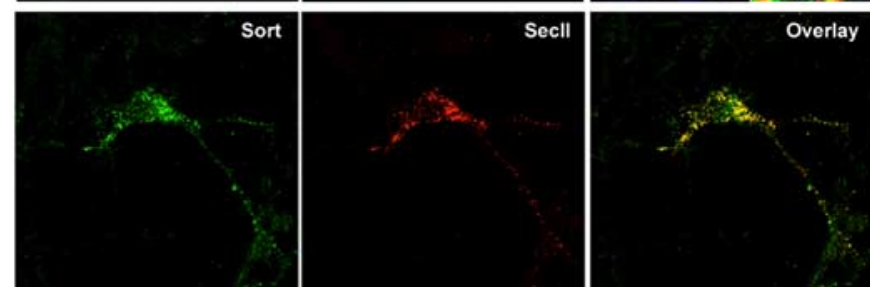

Figure 4. Subcellular colocalization of variant and wild-type BDNF with sortilin. A, Differentiated PC12 cells were transfected with N-terminal HA-tagged variant (Met) or wild-type BDNF (Val). Cells were fixed after $48 \mathrm{~h}$ and permeabilized. Colocalization of BDNF and sortilin was visualized by costaining with anti-HA and anti-sortilin antibodies. In addition, untransfected differentiated PC12 cells were fixed after $48 \mathrm{~h}$ and permeabilized. Colocalization of endogenous sortilin and Secll was visualized by costaining with anti-sortilin and anti-Secll antibodies. Representative epifluorescence images are shown. B, Hippocampal neurons were transfected with N-terminal HA-tagged variant (Met) or wild-type BDNF (Val) and Myc-tagged sortilin. Cells were fixed after $48 \mathrm{~h}$ and permeabilized. Colocalization of HA-BDNF and Myc-sortilin was visualized by confocal microscopy, as described in Materials and Methods, using epitope antibodies. All neurons were confirmed using MAP2 antibodies. In addition, untransfected neurons were fixed after $48 \mathrm{~h}$ and permeabilized. Colocalization of endogenous sortilin and Secll was visualized by costaining with anti-sortilin and anti-Secll antibodies. Representative epifluorescence images are shown. Scale bars, $20 \mu \mathrm{m}$.

www.jneurosci.org as supplemental material). This result suggests that the interaction of sortilin and BDNF is quite resistant to $\mathrm{pH}$ changes and suggests the possibility that in secretory granules, BDNF may not only be targeted to the same compartment but remain bound to the luminal domain of sortilin in this compartment.

\section{Truncated sortilin disrupts BDNF targeting to secretory granules}

To determine whether sortilin is necessary for targeting wild-type $\mathrm{BDNF}_{\mathrm{Val}}$ to secretory granules, we again used the use of a truncated sortilin construct lacking the transmembrane and cytoplasmic region of sortilin. We also added a Myc epitope tag in the $\mathrm{N}$-terminal region, which did not impair proBDNF binding (Fig. $3 A$ ). Differentiated PC12 cells were cotransfected with the Myctagged tSort as well as $\mathrm{HA}-\mathrm{BDNF} \mathrm{Val}_{\mathrm{Val}}$ and subsequently imaged for Myc and HA staining patterns. In the presence of truncated sortilin, $\mathrm{BDNF}_{\mathrm{Val}}$ was more diffusely distributed in the cell body, with minimal staining in the processes (Fig. 5A). Distribution of the truncated sortilin significantly overlapped with the staining pattern of the coexpressed $\mathrm{BDNF}_{\mathrm{Val}}$. When $\mathrm{HA}-\mathrm{BDNF}_{\mathrm{Met}}$ was coexpressed with the truncated sortilin, the same diffuse distribution of HA staining was observed as with the wild-type BDNF (data not shown). We subsequently quantitated the effect of the truncated sortilin on $\mathrm{HA}-\mathrm{BDNF}_{\mathrm{Val}}$ targeting to secretory granules in PC12 cells. We observed a significant low level of colocalization (Val plus tSort, $35 \pm 4 \%$; $p<0.01$; Student's $t$ test) of $\mathrm{BDNF}$ with secretory granule maker SecII in the presence of truncated sortilin. In contrast, in PC12 cells transfected with or without full-length sortilin, $\mathrm{BDNF}_{\mathrm{Val}}$ remained predominantly local- ized to SecII-positive punctate structures (Val, $77 \pm 5 \%$; Val plus Sort, $75 \pm 7 \%$ ). Furthermore, in cells transfected with full-length sortilin, $\mathrm{BDNF}_{\mathrm{Met}}$ showed decreased colocalization with SecII (Met plus Sort, $49 \pm 6 \%$ ), consistent with the results obtained in neurosecretory cells and neurons in the absence of overexpressed sortilin (Egan et al., 2003; Chen et al., 2004). We used a similar strategy in hippocampal neurons and noted that the truncated sortilin significantly decreased BDNF colocalization with SecII (control, $64 \pm 3 \%$; tSort, $13 \pm 2 \%$; $p<0.01$; Student's $t$ test). Together, these findings suggest that the truncated sortilin disrupts BDNF targeting to secretory granules.

\section{Role of sortilin-BDNF interaction in regulating BDNF secretion}

To assess the functional relevance of the BDNF prodomain interaction with sortilin, we performed two series of loss of function studies on neurotrophin secretion with (1) BDNF mutants and (2) a truncated sortilin mutant. First, we constructed GFP fusion proteins containing Box 1, Box 2, Box 3, and Box 2 plus 3, of which Box 2, Box 3, and Box 2 plus 3 all were able to disrupt interaction of BDNF with sortilin by coimmunoprecipitation studies (data not shown). We determined that in the presence of Box2-GFP or Box3-GFP, BDNF regulated secretion was decreased significantly (Box2-GFP, $63 \pm 6 \%$ of control; Box3GFP, $53 \pm 6 \%$; $p<0.001$ ) (Fig. 6A). Box2 plus 3-GFP was able to produce the largest disruption in regulated secretion (Box 2 plus $3-\mathrm{GFP}, 44 \pm 4 \%$ of control; $p<0.001$ ). As controls, GFP alone or Box1-GFP did not affect BDNF-sortilin interaction (data not shown) or affect regulated secretion of BDNF (Fig. $4 A$ ). Furthermore, BDNF mutants lacking Box 2, Box 3, or both Box 2 plus 3 
all demonstrated decreased regulated secretion compared with full-length BDNF (Fig. 6B). These loss of function studies suggest that a discrete BDNF prodomain region (amino acids 44-102), which interacts with sortilin, is required for efficient regulated $\mathrm{BDNF}$ secretion.

Second, to test the whether tSort also affects BDNF trafficking to the regulated secretory pathway, we measured regulated secretion of BDNF or NT-4 in PC12 cells in the presence and absence of tSort. In the case of NT-4, by ELISA analysis, we were able to detect NT-4 secreted in both a regulated and constitutive manner. Cotransfection with tSort led to no significant alteration in the amount of NT-4 secreted from either secretory pathway (Fig. 7A), which is consistent with the lack of interaction between sortilin and NT-4 (Fig. $1 A)$. In the case of BDNF, we were able to detect by ELISA BDNF secreted in a depolarization-dependent manner as well as decreased regulated secretion of $\mathrm{BDNF}_{\mathrm{Met}}$ compared with $\mathrm{BDNF}_{\mathrm{Val}}$ (Fig. $7 B)$. Cotransfection of tSort led to a significant decrease (54 $\pm 5 \% ; p<0.001)$ in $\mathrm{BDNF}_{\mathrm{Val}}$ regulated secretion. Interestingly, there was a concomitant increase $(48 \pm 5 \% ; p<0.01)$ in constitutively secreted $\mathrm{BDNF}_{\mathrm{Val}}$ (Fig. 7C). This finding suggests that altering the interaction of BDNF with sortilin leads to BDNF missorting from the regulated to constitutive secretory pathway. We used an additional control to confirm the specificity of this effect of $t$ Sort on $\mathrm{BDNF}_{\mathrm{Val}}$ secretion. Overexpressed full-length sortilin had minimal effect on either regulated or constitutive $\mathrm{BDNF}_{\mathrm{Val}}$ secretion (Fig. $7 \mathrm{~B}, \mathrm{C}$ ), suggesting that the levels of endogenous sortilin in PC12 cells (Fig. 4A) were sufficient to mediate BDNF trafficking.

Because $\mathrm{BDNF}_{\text {Met }}$ has been shown to have a decreased interaction with sortilin (Fig. $1 A$ ), we also determined the effect of tSort on $\mathrm{BDNF}_{\mathrm{Met}}$ secretion. Truncated sortilin had a diminished effect of decreasing the proportion of $\mathrm{BDNF}_{\mathrm{Met}}$ secreted in a regulated manner compared with the effect on $\mathrm{BDNF}_{\text {Val }}$ (Met plus tSort, $32 \pm 7 \%$ decrease; Val plus tSort, $58 \pm 5 \%$ decrease) (Fig. $5 A$ ). However, the absolute level of $\mathrm{BDNF}_{\text {Met }}$ secreted in the presence of tSort $(327 \pm 38 \mathrm{pg} / \mathrm{ml})$ was equivalent to that of $\mathrm{BDNF}_{\mathrm{Val}}$ secreted in the presence of tSort $(337 \pm 41 \mathrm{pg} / \mathrm{ml})$. This result suggests that the impaired $\mathrm{BDNF}_{\mathrm{Met}}$ regulated secretion observed in Figure $7 \mathrm{~A}$, and in previous studies (Egan et al., 2003; Chen et al., 2004) may be linked to its decreased interaction with sortilin.

To confirm these findings on BDNF secretion in cells endogenously producing and secreting BDNF, we performed a similar series of secretion studies in primary hippocampo-cortical neuronal cultures. We were able to detect regulated and constitutive secretion of transfected BDNF from these cultured neurons (Fig. $8 A, B)$. Cotransfection of tSort led to a significant decrease ( $53 \pm$

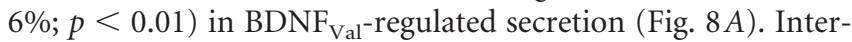

A
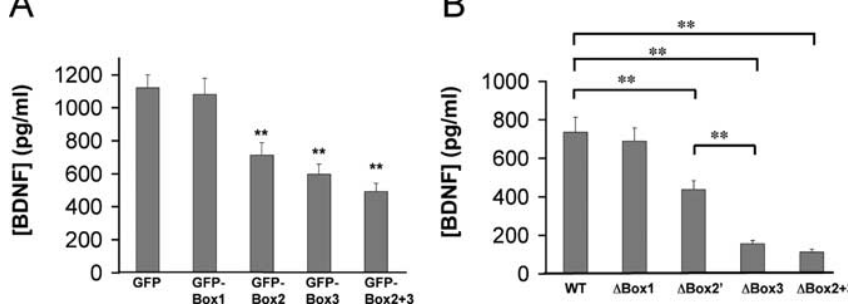

Figure 6. Role of the BDNF prodomain on activity-dependent BDNF secretion. $A$, Lentiviral constructs containing differential regions of the BDNF prodomain (Box1, Box2, Box3, Box2 + 3) fused to GFP or GFP alone were expressed in PC12 cells transfected with N-terminal HA-BDNF. After $48 \mathrm{~h}$, media were collected under depolarization secretion conditions, as described in Materials and Methods, and analyzed by ELISA. Results are presented as a mean \pm SEM determined from six independent experiments $\left({ }^{* *} p<0.001\right.$; Student's $t$ test). $B$, Differentiated $\mathrm{PC1} 2$ cells were transfected with mutant forms of BDNF lacking certain regions of the prodomain $\left(\triangle B \times x 1, \Delta B o \times 2^{\prime}, \Delta B o \times 3, \Delta B 0 \times 2+3\right)$. After $48 \mathrm{~h}$, media were collected under depolarization secretion conditions, as described in Materials and Methods, and analyzed by ELISA. Results are presented as a mean \pm SEM determined from analysis of six independent experiments $\left({ }^{* *} p<0.001\right.$; Student's $t$ test). WT, Wild type. 
A
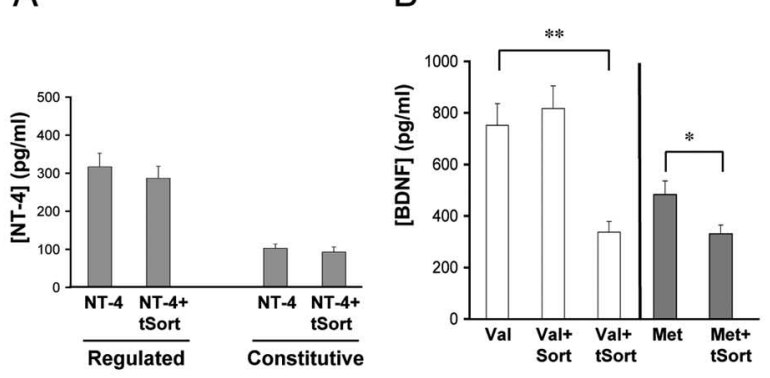

Regulated
C

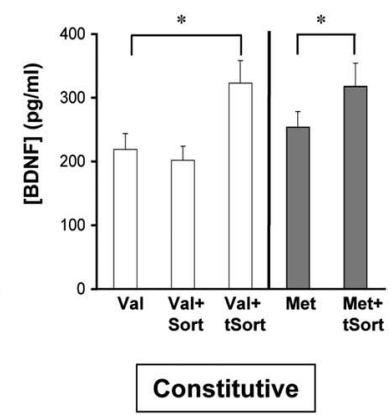

Figure 7. Truncated sortilin selectively alters activity-dependent BDNF secretion. $A$, Differentiated $\mathrm{PC} 12$ cells were transfected with NT-4 in the presence or absence of tSort. After $48 \mathrm{~h}$, media were collected under depolarization and constitutive secretion conditions, as described in Materials and Methods, and analyzed by ELISA. Differentiated PC12 cells were transfected with BDNF in the presence or absence of full-length sortilin (Sort) or tSort. After $48 \mathrm{~h}$, media were collected under depolarization $(\boldsymbol{B})$ and constitutive secretion $(\boldsymbol{C}$ conditions, as described in Materials and Methods, and analyzed by ELISA. All results are presented as a mean \pm SEM determined from analysis of six independent experiments $\left({ }^{*} p<0.01 ;{ }^{* *} p<0.001\right.$; Student's $t$ test).

A

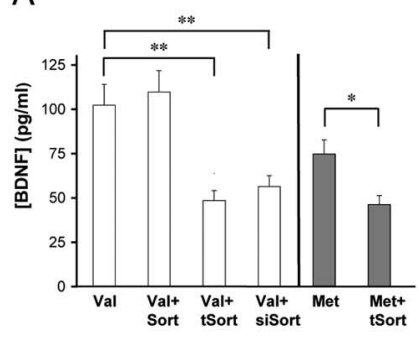

Regulated
B

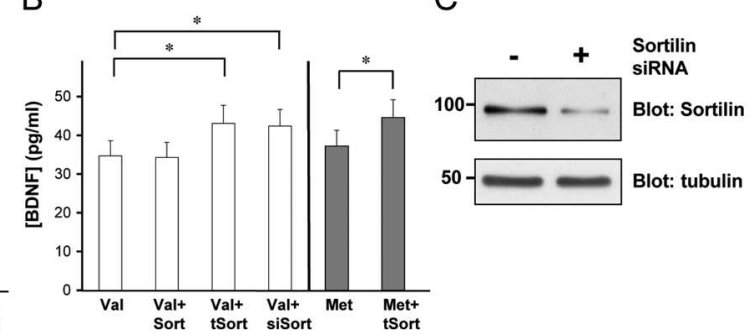

Figure 8. Truncated sortilin and sortilin siRNA selectively alter activity-dependent BDNF secretion. Hippocampo-cortical neurons were transfected with BDNF in the presence or absence of full-length sortilin (Sort), tSort, or sortilin siRNA (siSort). After $3 \mathrm{~d}$, media were collected under depolarization $(\boldsymbol{A})$ and constitutive secretion $(\boldsymbol{B})$ conditions, as described in Materials and Methods, and analyzed by ELISA. All results are presented as a mean \pm SEM determined from analysis of six independent experiments $\left({ }^{*} p<0.05 ;{ }^{* *} p<0.01\right.$; Student's $t$ test). C, Hippocampo-cortical neurons were transfected in the presence or absence of sortilin siRNA. After $3 \mathrm{~d}$, cells lysates were immunoblotted for and sortilin and tubulin (loading control) as described in Materials and Methods.

estingly again, there was a concomitant increase $(25 \pm 9 \%$; $p<$ $0.05)$ in constitutively secreted $\mathrm{BDNF}_{\mathrm{Val}}$ (Fig. $8 B$ ). Overexpressed full-length sortilin had minimal effect on either regulated or constitutive $\mathrm{BDNF}_{\mathrm{Val}}$ secretion (Fig. $8 B, C$ ). To determine further the specificity of the role of sortilin in BDNF regulated secretion, we assessed the effect of reducing endogenous sortilin levels by small interfering RNA (siRNA) in these neurons. We transfected duplex sortilin RNA oligonucleotides determined previously to significantly reduce sortilin levels (Lefrancois et al., 2003, 2005). Importantly, the sortilin siRNA sequence used is not found in other Vps10p family members (Sorcs1, Sorcs2, Sorcs3, SorLa) and thus allows for specific knock-down of sortilin. Transfection of the duplex sortilin RNA oligonucleotides in these neurons led to a significant reduction in endogenous sortilin levels, as assessed by Western blot analysis (Fig. 8C). Cotransfection of the siRNA with $\mathrm{BDNF}_{\mathrm{Val}}$ led to a significant decrease (45 \pm $8 \% ; p<0.01$ ) in $\mathrm{BDNF}_{\mathrm{Val}^{-}}$-regulated secretion (Fig. $8 A$ ), with a concomitant increase $(20 \pm 8 \%$; $p<0.05)$ in constitutively secreted $\mathrm{BDNF}_{\mathrm{Val}}(\mathrm{Fig} .8 \mathrm{~B})$. In all, these findings in cell lines and primary neurons demonstrate that sortilin through its interaction with the BDNF prodomain selectively regulates the sorting of BDNF into the regulated secretory pathway, the primary means of BDNF secretion in neurosecretory cells and neurons.

\section{Discussion}

Trafficking of newly synthesized BDNF to secretory pathways is a complex, highly regulated process, which requires appropriate targeting to secretory granules destined for release. The regulatory mechanisms controlling this process are not known. The recent human variant in the BDNF prodomain (Val66Met) that has impaired regulated secretion has provided a tool to gain potential insights in that it suggests that a trafficking signal in the prodomain is involved in optimal BDNF targeting to the regulated secretory pathway. From our studies, we conclude that in neurosecretory cells and neurons, efficient BDNF sorting to regulated secretory pathways is controlled by a protein interaction involving a region in the prodomain encompassing the Met substitution. We propose that this sorting operation is mediated by an interaction with a Vps10p domain protein, sortilin, that has been established previously to have multifunctional roles in intracellular trafficking of polypeptide cargo from the Golgi apparatus to secretory and endocytic pathways (Petersen et al., 1997; Mazella et al., 1998; Munck Petersen et al., 1999; Nielsen et al., 1999; Lefrancois et al., 2003).

Our studies have provided three new insights into the regulation of BDNF trafficking to secretory pathways. First, we have mapped a region in the BDNF prodomain (amino acids 44-102) that is responsible for interaction with the luminal domain of sortilin and demonstrated endogenous interaction of the two molecules in brain lysates (Fig. $1 F$ ) as well as localization in the same secretory granule compartment in neurons (Fig. 2). Sequence comparison of this prodomain region in BDNF demonstrates that there is marked similarity with NGF, in particular in Box 3. However, despite sequence similarities, this region may serve different functions for these two neurotrophins. First, previous studies have shown that deletion of the corresponding Box 3 in NGF has led to decreased expression of NGF protein, suggesting that this region is possibly required possibly for proper folding of the protein (Suter et al., 1991). Deletion of Box 3 in BDNF does not alter expression levels of BDNF protein (Fig. 1C) but does significantly reduce its regulated secretion (Fig. 4B). Second, it is also notable that although it has been established that the majority of NGF is cleaved to mature forms in the Golgi apparatus, the majority of BDNF remains in the proform intracellularly and may be released as a proform (Mowla et al., 1999; Chen et al., 2004; Pang et al., 2004). In this context, the BDNF prodomain is capable of playing additional roles in post-Golgi trafficking of BDNF than in the parallel case for NGF. Interestingly, another putative sorting motif was recently mapped to the mature domain of BDNF (Lou et al., 2005) consisting of four residues (I144, E146, I233, D234), which interacts with a sorting protein, carboxypeptidase E. Mutation of the acidic residues (E146, D234) to alanines led to missorting of 
BDNF to the constitutive pathway. Together with our present findings, this study suggests multiple levels of regulation for BDNF trafficking to the secretory pathways. Furthermore, the prodomain of NT-4, which has only minimal sequence similarity with the prodomain of BDNF or NGF, showed no interaction with sortilin. These results provide evidence that BDNF interaction with sortilin occurs in a prodomain region that may be uniquely required for its efficient regulated secretion from neurons.

Second, identification of the sortilin-proBDNF interaction provides a plausible molecular model of understanding the trafficking defect found in the human variant $\mathrm{BDNF}_{\mathrm{Met}}$. The Met substitution at position 66 significantly decreases BDNF interaction with sortilin. The Met substitution has been shown to lead to decreased colocalization with secretory granules and decreased regulated secretion of $\mathrm{BDNF}_{\mathrm{Met}}$ from neurosecretory cells as well as from hippocampal neurons (Egan et al., 2003; Chen et al., 2004). In this context, our results imply that decreased protein interaction with sortilin plays a direct role in the defective trafficking of $\mathrm{BDNF}_{\mathrm{Met}}$ into the regulated secretory pathway and provides a valuable molecular link for future studies that attempt to understand how mistrafficking of this variant BDNF leads to selective impairment of CNS function.

Third, the role of sortilin in determining BDNF trafficking to secretory pathways in neurons has general implications for trafficking and secretion of the other neurotrophins. In our studies in neurosecretory cells, as well as hippocampal neurons, endogenous sortilin appears to be localized in the same punctate secretory granule compartment as BDNF (Fig. 4). Because a type 1 transmembrane protein targeted to secretory granules, the luminal domain of which binds to BDNF, sortilin is correctly positioned to be involved in appropriate membrane sorting and retention of BDNF in this compartment. In this context, most previous subcellular localization studies of sortilin were performed in cells lacking regulatory secretory pathways (Petersen et al., 1997; Nielsen et al., 1999, 2001; Lefrancois et al., 2003). In one previous study, sortilin was localized in cortical, hippocampal, and cerebellar neurons to a variety of compartments, including vesicular organelles (Sarret et al., 2003). We cannot exclude that overexpression of the truncated sortilin may affect sorting of proBDNF by competing out binding to another unidentified sorting protein. However, the loss of function studies with sortilin siRNA (Fig. 8) provide evidence that sortilin specifically is involved regulating BDNF secretion in neurons, because the RNA sequence used is unique to sortilin and not in the other Vps10p family members (Sorcs1, Sorcs2, Sorcs3, SorLa).

The efficient trafficking and regulated secretion of NT-4 under the same conditions that disrupted BDNF trafficking and secretion indicates that the sortilin may specifically control trafficking of certain neurotrophins and does not serve a general trafficking function. It should be noted although that regulated secretion of NT-4 has been observed previously in PC12 cells (Kruttgen et al., 1998) but also has not been observed in other neurosecretory cells (Hibbert et al., 2003). This finding also implies that NT-4 trafficking to these secretory pathways is likely controlled by another set of sorting proteins. Because the truncated form of sortilin contains the entire Vps10p domain, other members of the Vps10p domain family (sorLA, SorCS1, SorCS2, SorCS3) will not likely be involved in NT-4 sorting. It is plausible that the evolution of their distinctly divergent prodomain sequences, which maintaining very similar mature domains, al- lowed for differential regulation of sorting of BDNF and NT-4 to secretory pathways while still activating the same neurotrophin receptor, TrkB.

In this context, these findings shed new light into potential mechanisms by which these two ligands for the same receptor can be regulated and lead to different biological functions. Previous analysis of the transgenic knock-out mice for NT-4 and BDNF have determined that there are differences in these two neurotrophins roles in hippocampal synaptic transmission, and hippocampal dependent behavior. In NT-4 knock-out mice, the long-lasting form of long-term potentiation (LTP) in Schaffer collateral CA1 synapses was selectively affected (Xie et al., 2000), whereas both short- and long-term forms of LTP in the hippocampus are affected in the BDNF knock-out mice (Korte et al., 1995, 1998; Patterson et al., 1996). In addition, in behavioral tests, long-term memory was selectively affected by loss of NT-4 (Xie et al., 2000), whereas both short- and long-term memory are affected by loss of BDNF (Linnarsson et al., 1997; Minichiello et al., 1999; Gorski et al., 2003). Previous studies have suggested that subtle differences in NT-4 and BDNF activation of TrkB and in downstream signaling pathways may mediate these differences (Klein et al., 1992; Minichiello et al., 1998; Fan et al., 2000). Our findings suggest that presynaptic sorting of NT-4 and BDNF to secretory pathways may provide a more divergent point of regulation that may explain the differences in activity-dependent biological functions of the two neurotrophins. Thus, in the future, identification of the appropriate sorting molecules controlling NT-4 trafficking will allow for direct comparison of differences in regulation BDNF and NT-4 sorting to secretory pathways in neurons.

In all, BDNF is primarily secreted from neurons in an activitydependent manner, after which it can have a variety of biological effects such as modulating synaptic transmission and synaptic plasticity. Our studies have identified a sorting mechanism involving unique sequence elements in the BDNF prodomain, as well as a sorting protein that specifically mediates this trafficking decision to the regulated secretory pathway. Our studies suggest a new framework, based on divergent presynaptic regulation of sorting to secretory pathways, to reconcile how two ligands for the TrkB neurotrophin receptor, BDNF and NT-4, can mediate diverse biological responses.

\section{References}

Berg EA, Johnson RJ, Leeman SE, Boyd N, Kimerer L, Fine RE (2000) Isolation and characterization of substance P-containing dense core vesicles from rabbit optic nerve and termini. J Neurosci Res 62:830-839.

Berkemeier LR, Winslow JW, Kaplan DR, Nikolics K, Goeddel DV, Rosenthal A (1991) Neurotrophin-5: a novel neurotrophic factor that activates trk and trkB. Neuron 7:857-866.

Chao MV (2003) Neurotrophins and their receptors: a convergence point for many signalling pathways. Nat Rev Neurosci 4:299-309.

Chen ZY, Patel PD, Sant G, Meng CX, Teng KK, Hempstead BL, Lee FS (2004) Variant brain-derived neurotrophic factor (BDNF) (Met66) alters the intracellular trafficking and activity-dependent secretion of wildtype BDNF in neurosecretory cells and cortical neurons. J Neurosci 24:4401-4411.

Egan M, Kojima M, Callicott J, Goldberg T, Kolachana B, Bertolino A, Zaitsev E, Gold B, Goldman D, Dean M, Lu B, Weinberger D (2003) The BDNF val66met polymorphism affects activity-dependent secretion of BDNF and human memory and hippocampal function. Cell 112:257-269.

Fan G, Egles C, Sun Y, Minichiello L, Renger JJ, Klein R, Liu G, Jaenisch R 
(2000) Knocking the NT4 gene into the BDNF locus rescues BDNF deficient mice and reveals distinct NT4 and BDNF activities. Nat Neurosci 3:350-357.

Gomez-Foix AM, Coats WS, Baque S, Alam T, Gerard RD, Newgard CB (1992) Adenovirus-mediated transfer of the muscle glycogen phosphorylase gene into hepatocytes confers altered regulation of glycogen metabolism. J Biol Chem 267:25129-25134.

Gorski JA, Balogh SA, Wehner JM, Jones KR (2003) Learning deficits in forebrain-restricted brain-derived neurotrophic factor mutant mice. Neuroscience 121:341-354.

Gresch O, Engel FB, Nesic D, Tran TT, England HM, Hickman ES, Korner I, Gan L, Chen S, Castro-Obregon S, Hammermann R, Wolf J, MullerHartmann H, Nix M, Siebenkotten G, Kraus G, Lun K (2004) New nonviral method for gene transfer into primary cells. Methods 33:151-163.

Halban PA, Irminger JC (1994) Sorting and processing of secretory proteins. Biochem J 299:1-18.

Hallbook F, Ibanez CF, Persson H (1991) Evolutionary studies of the nerve growth factor family reveal a novel member abundantly expressed in Xenopus ovary. Neuron 6:845-858.

Hariri AR, Goldberg TE, Mattay VS, Kolachana BS, Callicott JH, Egan MF, Weinberger DR (2003) Brain-derived neurotrophic factor val66met polymorphism affects human memory-related hippocampal activity and predicts memory performance. J Neurosci 23:6690-6694.

Hempstead BL, Rabin SJ, Kaplan L, Reid S, Parada LF, Kaplan DR (1992) Overexpression of the trk tyrosine kinase rapidly accelerates nerve growth factor-induced differentiation. Neuron 9:883-896.

Hibbert AP, Morris SJ, Seidah NG, Murphy RA (2003) Neurotrophin-4, alone or heterodimerized with brain-derived neurotrophic factor, is sorted to the constitutive secretory pathway. J Biol Chem 278:48129-48136.

Huang E, Reichardt L (2001) Neurotrophins: roles in neuronal development and function. Annu Rev Neurosci 24:677-736.

Huttner WB, Gerdes HH, Rosa P (1991) The granin (chromogranin/secretogranin) family. Trends Biochem Sci 16:27-30.

Hutton JC (1982) The internal pH and membrane potential of the insulinsecretory granule. Biochem J 204:171-178.

Ip NY, Ibanez CF, Nye SH, McClain J, Jones PF, Gies DR, Belluscio L, Lebeau MM, Espinosa R, Squinto SP, Persson H, Yancopoulos GD (1992) Mammalian neurotrophin-4-structure, chromosomal localization, tissue distribution, and receptor specificity. Proc Natl Acad Sci USA 89:3060-3064.

Johnson RG, Scarpa A (1976) Internal pH of isolated chromaffin vesicles. J Biol Chem 251:2189-2191.

Klein R, Lamballe F, Bryant S, Barbacid M (1992) The trkB tyrosine protein kinase is a receptor for neurotrophin-4. Neuron 8:947-956.

Korte M, Carroll P, Wolf E, Brem G, Thoenen H, Bonhoeffer T (1995) Hippocampal long-term potentiation is impaired in mice lacking brain-derived neurotrophic factor. Proc Natl Acad Sci USA 92: $8856-8860$.

Korte M, Kang H, Bonhoeffer T, Schuman E (1998) A role for BDNF in the late-phase of hippocampal long-term potentiation. Neuropharmacology 37:553-559.

Kruttgen A, Moller JC, Heymach Jr JV, Shooter EM (1998) Neurotrophins induce release of neurotrophins by the regulated secretory pathway. Proc Natl Acad Sci USA 95:9614-9619.

Lee F, Chao M (2001) Activation of Trk neurotrophin receptors in the absence of neurotrophins. Proc Natl Acad Sci USA 92:3555-3560.

Lee R, Kermani P, Teng K, Hempstead B (2001) Regulation of cell survival by secreted proneurotrophins. Science 294:1945-1948.

Lefrancois S, Zeng J, Hassan AJ, Canuel M, Morales CR (2003) The lysosomal trafficking of sphingolipid activator proteins (SAPs) is mediated by sortilin. EMBO J 22:6430-6437.

Lefrancois S, Canuel M, Zeng J, Morales CR (2005) Inactivation of sortilin (a novel lysosomal sorting receptor) by dominant negative competition and RNA interference. Biol Proced Online 7:17-25.

Linnarsson S, Bjorklund A, Ernfors P (1997) Learning deficit in BDNF mutant mice. Eur J Neurosci 9:2581-2587.

Lou H, Kim SK, Zaitsev E, Snell CR, Lu B, Loh YP (2005) Sorting and activity-dependent secretion of BDNF require interaction of a specific motif with the sorting receptor carboxypeptidase e. Neuron 45: 245-255.
Lu B (2003) Pro-region of neurotrophins. Role in synaptic modulation. Neuron 39:735-738.

Mazella J (2001) Sortilin/neurotensin receptor-3: a new tool to investigate neurotensin signaling and cellular trafficking? Cell Signal 13:1-6.

Mazella J, Zsurger N, Navarro V, Chabry J, Kaghad M, Caput D, Ferrara P, Vita N, Gully D, Maffrand JP, Vincent JP (1998) The 100-kDa neurotensin receptor is gp95/sortilin, a non-G-protein-coupled receptor. J Biol Chem 273:26273-26276.

McGrory WJ, Bautista DS, Graham FL (1988) A simple technique for the rescue of early region I mutations into infectious human adenovirus type 5. Virology 163:614-617.

Minichiello L, Casagranda F, Tatche RS, Stucky CL, Postigo A, Lewin GR, Davies AM, Klein R (1998) Point mutation in trkB causes loss of NT4dependent neurons without major effects on diverse BDNF responses. Neuron 21:335-345.

Minichiello L, Korte M, Wolfer D, Kuhn R, Unsicker K, Cestari V, RossiArnaud C, Lipp HP, Bonhoeffer T, Klein R (1999) Essential role for TrkB receptors in hippocampus-mediated learning. Neuron 24:401-414.

Moller J, Kruttgen A, Heymach JJ, Ghori N, Shooter E (1998) Subcellular localization of epitope-tagged neurotrophins in neuroendocrine cells. J Neurosci Res 51:463-472.

Momose Y, Murata M, Kobayashi K, Tachikawa M, Nakabayashi Y, Kanazawa I, Toda T (2002) Association studies of multiple candidate genes for Parkinson's disease using single nucleotide polymorphisms. Ann Neurol 51:133-136.

Mowla S, Pareek S, Farhadi H, Petrecca K, Fawcett J, Seidah N, Morris S, Sossin W, Murphy R (1999) Differential sorting of nerve growth factor and brain-derived neurotrophic factor in hippocampal neurons. J Neurosci 19:2069-2080.

Munck Petersen C, Nielsen MS, Jacobsen C, Tauris J, Jacobsen L, Gliemann J, Moestrup SK, Madsen P (1999) Propeptide cleavage conditions sortilin/ neurotensin receptor-3 for ligand binding. EMBO J 18:595-604.

Neves-Pereira M, Mundo E, Muglia P, King N, Macciardi F, Kennedy J (2002) The brain-derived neurotrophic factor gene confers susceptibility to bipolar disorder: evidence from a family-based association study. Am J Hum Genet 71:651-655.

Nielsen MS, Jacobsen C, Olivecrona G, Gliemann J, Petersen CM (1999) Sortilin/neurotensin receptor-3 binds and mediates degradation of lipoprotein lipase. J Biol Chem 274:8832-8836.

Nielsen MS, Madsen P, Christensen EI, Nykjaer A, Gliemann J, Kasper D, Pohlmann R, Petersen CM (2001) The sortilin cytoplasmic tail conveys Golgi-endosome transport and binds the VHS domain of the GGA2 sorting protein. EMBO J 20:2180-2190.

Nykjaer A, Lee R, Teng KK, Jansen P, Madsen P, Nielsen MS, Jacobsen C, Kliemannel M, Schwarz E, Willnow TE, Hempstead BL, Petersen CM (2004) Sortilin is essential for proNGF-induced neuronal cell death. Nature 427:843-848.

Ozawa H, Takata K (1995) The granin family-its role in sorting and secretory granule formation. Cell Struct Funct 20:415-420.

Pang PT, Teng HK, Zaitsev E, Woo NT, Sakata K, Zhen S, Teng KK, Yung WH, Hempstead BL, Lu B (2004) Cleavage of proBDNF by tPA/plasmin is essential for long-term hippocampal plasticity. Science 306:487-491.

Patterson S, Abel T, Deuel T, Martin K, Rose J, Kandel E (1996) Recombinant BDNF rescues deficits in basal synaptic transmission and hippocampal LTP in BDNF knockout mice. Neuron 16:1137-1145.

Petersen CM, Nielsen MS, Nykjaer A, Jacobsen L, Tommerup N, Rasmussen HH, Roigaard H, Gliemann J, Madsen P, Moestrup SK (1997) Molecular identification of a novel candidate sorting receptor purified from human brain by receptor-associated protein affinity chromatography. J Biol Chem 272:3599-3605.

Rybakowski JK, Borkowska A, Czerski PM, Skibinska M, Hauser J (2003) Polymorphism of the brain-derived neurotrophic factor gene and performance on a cognitive prefrontal test in bipolar patients. Bipolar Disord 5:468-472.

Sarret P, Krzywkowski P, Segal L, Nielsen MS, Petersen CM, Mazella J, Stroh T, Beaudet A (2003) Distribution of NTS3 receptor/sortilin mRNA and protein in the rat central nervous system. J Comp Neurol 461:483-505.

Sen S, Nesse R, Stoltenberg S, Li S, Gleiberman L, Chakravarti A, Weder A, 
Burmeister M (2003) A BDNF coding variant is associated with the NEO personality inventory domain neuroticism, a risk factor for depression. Neuropsychopharmacology 28:397-401.

Sklar P, Gabriel S, McInnis M, Bennett P, Lim Y, Tsan G, Schaffner S, Kirov G, Jones I, Owen M, Craddock N, DePaulo JR, Lander E (2002) Familybased association study of 76 candidate genes in bipolar disorder: BDNF is a potential risk locus. Brain-derived neutrophic factor. Mol Psychiatry 7:579-593.

Suter U, Heymach J, Shooter E (1991) Two conserved domains in the NGF polypeptide are necessary and sufficient for the biosynthesis of correctly processed and biologically active NGF. EMBO J 10:2394-2400.

Tessarollo L (1998) Pleiotropic functions of neurotrophins in development. Cytokine Growth Factor Rev 9:125-137.
Ventriglia M, Bocchio Chiavetto L, Benussi L, Binetti G, Zanetti O, Riva MA, Gennarelli M (2002) Association between the BDNF 196 A/G polymorphism and sporadic Alzheimer's disease. Mol Psychiatry 7:136-137.

Wang LC, Meijer HK, Humbel BM, Jenks BG, Roubos EW (2004) Activity-dependent dynamics of coexisting brain-derived neurotrophic factor, pro-opiomelanocortin and alpha-melanophorestimulating hormone in melanotrope cells of Xenopus laevis. J Neuroendocrinol 16:19-25.

Xie C, Sayah D, Chen Q, Wei W, Smith D, Liu X (2000) Deficient longterm memory and long-lasting long-term potentiation in mice with a targeted deletion of neurotrophin-4. Proc Natl Acad Sci USA 97: $8116-8121$. 